\title{
Influence of laser remelting on surface topography and chemical component of K423A nickel-base superalloy
}

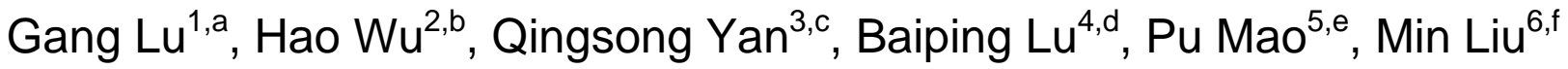 \\ ${ }^{1,2,3,4,5,6}$ National Defence Key Discipline Laboratory of Light Alloy Processing Science and \\ Technology, Nanchang Hangkong University, Nanchang, Jiangxi, 330063, China \\ aemail: aimulalg@163.com, bemail:280847386@qq.com, 'cemail: yanqs1973@126.com, \\ demail: Ibp029@yahoo.com.cn, ${ }^{\mathrm{e} e m a i l}$ :376591037@qq.com, ${ }^{\dagger}$ email: 532319375@qq.com
}

Keywords: Laser remelting; Superalloy; K423A; Laser process parameters.

\begin{abstract}
Through analyzing and testing the microstructure and chemical component of the samples after laser remelting, the influence of laser remelting on K423A nickel-base superalloy were studied. The results showed that, laser remelting had a significant influence on surface topography of K423A nickel-base superalloy. With the increasing of laser power, the laser molten pool grew in both depth and width. The Similar situations occurred with the increasing of laser frequency. Meanwhile, the influence on chemical component of K432A was not that obvious. The content of major elements changed little, but $\mathrm{Al}$ content reduced.
\end{abstract}

\section{Introduction}

With the improvement of laser technology, laser has become a new effective means of material surface modification [1, 2, 3, 4]. Laser remelting is a kind of laser surface strengthening technology which is combining laser technology and heat treatment, and it is also advanced coating technology of high performance surface, this technology can change the surface properties of materials, and it can guarantee the metallurgical combination of coating and the substrate $[5,6,7]$. Laser remelting generally do not add any other alloy elements, melting layer and substrate material is metallurgical combination of natural.

Nickel-base superalloy is based on nickel substrate; it has high strength, good oxidation resistance and corrosion resistance [8, 9]. Nickel-base superalloy has good comprehensive properties, it's widely used in aerospace and other industrial sectors [10, 11].

This paper focuses on the application of laser remelting on K423A nickel-base superalloy which is one of the main materials of cartridge receiver. Among the post-treatment techniques for surface strengthening, the combination of laser remelting and nickel-base superalloy can promote the development of disciplines and industries.

\section{Experimental procedure}

The experiment adopted K423A nickel-base superalloy as substrate material, samples were cut into slabs with the size of $50 \mathrm{~mm} \times 30 \mathrm{~mm} \times 5 \mathrm{~mm}$, the chemical compositions are shown in table 1.Inlay and preheat the samples before the experiment begin: the samples were soak in $10 \% \mathrm{NaOH}$ aqueous solution for $5 \mathrm{~min}$, then wipe clean with aceton, finally put the samples into holding furnace for preheating, the preheating temperature is $200^{\circ} \mathrm{C} \sim 300^{\circ} \mathrm{C}$

\begin{tabular}{ccccccc}
\multicolumn{7}{c}{ Table 1 Composition of K423A (wt.-\%) } \\
\hline C & Cr & Ni & Co & Mo & Al & Ti \\
$0.12 \sim 0.18$ & $14.0 \sim 15.5$ & $56 \sim 63$ & $8.2 \sim 8.9$ & $6.8 \sim 8.3$ & $3.9 \sim 4.4$ & $3.4 \sim 4.8$ \\
\hline
\end{tabular}

The experimental equipment is L80 laser welder, laser process parameters contain: power, frequency and welding width. Seven different combinations of laser remelting process parameters were performed on three K423A samples, the melted area was shielded with a continuous flow of 
argon gas to avoid oxidation, and the flow rate was 5L / min. The laser remelting process parameters were shown in table 2.

Table 2 Laser remelting process parameters of the experiment

\begin{tabular}{ccccc}
\hline Sample & No & Power/ $(\mathbf{W})$ & Width/ (mm) & Frequency/ (Hz) \\
\hline \multirow{2}{*}{1} & 1 & 30 & 6 & 6 \\
& 2 & 35 & 6 & 6 \\
2 & 3 & 40 & 6 & 6 \\
2 & 4 & 35 & 4 & 6 \\
& 5 & 35 & 6 & 6 \\
3 & 6 & 35 & 6 & 2 \\
& 7 & 35 & 6 & 4 \\
\hline
\end{tabular}

Scanning electron microscopic (SEM) and Energy Dispersive Spectroscopy (EDS) experiment were carried out after laser remelting, and then analyzed and compared the change of the data before and after the experiment.

\section{Results and discussion}

\section{Influence on surface topography}

Fig. 1 shows the surface morphology of the samples after laser remelting. The recessed portion was the remelted zone and heat affected zone, the circle was the end of the laser process, which was the position of the laser stopped moving.
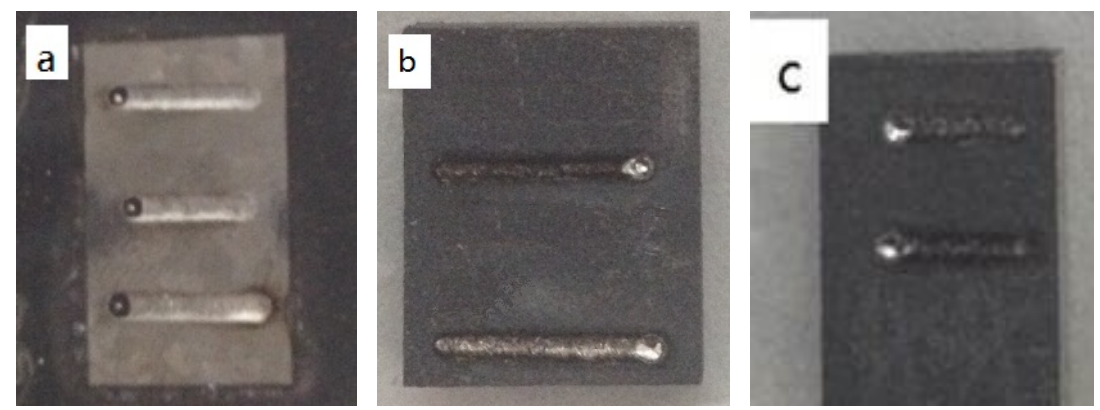

Fig.1. The surface topography of samples: (a) sample 1 (b) sample 2 (c) sample 3

According to fig.1, with the increasing of laser power, the depth of the laser molten pool and the width increased; with the laser scanning, the laser molten pool was gradually widened because of heat dissipation during the remelting process.

Laser frequency directly reflected the time laser beam stayed in the material surface, under the condition of other parameters were the same, the higher the frequency, the longer time laser beam effected on the surface of material, so the temperature increased, lead to the melting of material surface and the deepen of laser molten pool. So, low laser frequency lead opposite situation. The laser molten pool was shown in fig.2.

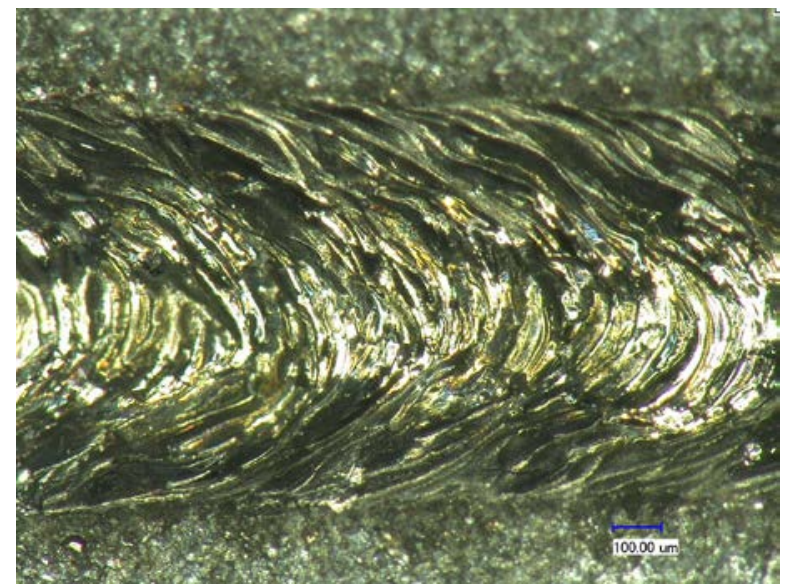

Fig.2. Laser molten pool 
Seen from fig.2, laser beam left obvious melting layer and transformation hardening layer on K423A surface, there were numbers of microcracks in the laser molten pool. The two main reasons for the cracks, one was that there were a great stress in melting layer, the other was uneven solidification. Laser remelting process is the process that material surface was re-heating by laser, in this process, material suffered re-melted and solidified.

\section{Influence on microstructure and chemical component}
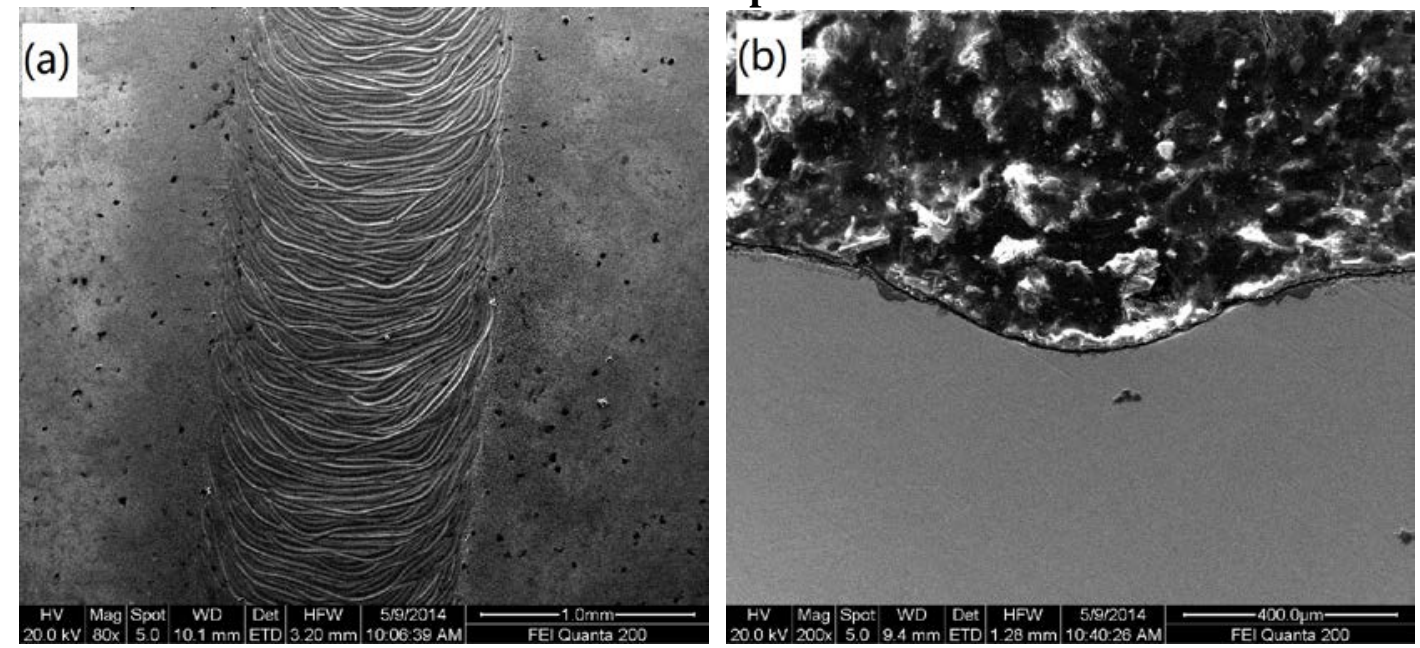

Fig.3. SEM images of remelted area: (a) cross section of remelted area (b) longitudinal section of remelted area

According to fig.3, laser surface remelting led to several types of microstructural changes, which depended on the composition and the original states of the alloys treated._As in the low temperature of the alloy has good thermal conductivity and the laser itself has self-chilling effective, meanwhile, argon gas accelerated the cooling of remelted area, a great degree of supercooling was caused, the molten pool solidified instantly, crystalline structure was refined, it made the surface strengthening. Many experimental results show that, the optimized process parameters can make the grain refinement to $5 \%$ to $10 \%$ of the original.


Fig.4 SEM and EDS images of remelted area

According to fig.4, laser remelting would cause selected melting and evaporation on the surface of samples. Energy spectrum results show that Al content was between 0.9 and 6.54, and the average value was $3.52 \%$, it was a bit lower than that in the basal body which is 4.4 . This was mainly because $\mathrm{Al}$ was vaporized under high temperature of laser, which reduced the $\mathrm{Al}$ content. When laser power increased, this phenomenon became more obvious. Mo content was between 8.83 and 11.21, and the average value was $10.30 \%$, it was a bit higher than that in the basal body which was 7.55 . Ti content was between 1.30 and 5.51, the average value was $4.06 \%$. Cr content was between 10.04 and 21.86, the average value was $14.25 \%$. Ni content was between 45.4 and 60.77 , the average value was $55.48 \%$. The major elements in the alloy did not change significantly under high temperature of laser. 


\section{Conclusion}

(1) Laser remelting process parameters had a great influence on surface topography of K423A, the deeper the laser power is, the deeper and the wider the laser molten pool is, the higher the laser frequency is, the longer time laser beam effected on the surface of material.

(2) Laser remelting has limited influence on the chemical component of K432A, the major elements do not change significantly. With the increase of the laser power, the organization becomes dense, the grain can be refined.

(3) Appropriate laser remelting process parameters can improve the surface properties of material.

\section{Acknowledgements}

This research was financially supported by the national natural science fund of China (51261025), Jiangxi Province Youth Science Fund (20142BAB216024), State Key Laboratory of Materials Processing and Die \& Mould Technology, Huazhong University of Science and Technology (P2014-009).

\section{References}

[1]. Y.C. Hong, Z.W. Xia: Actuality and evolvement of surfacing improvement by laser remelting on different matrixes and layers [J]. Electric Welding Machine, Vol.35(2005), p.6-11

[2]. Y.Q. Cheng, W. Fu, G.C. Ji: Study on erosion properties of $\mathrm{Cr}_{3} \mathrm{C}_{2}-\mathrm{NiCr}$ coating remelting with different laser parameters [J]. Hot working Technology, Vol. 39(2010), p. 76-78.

[3]. T. Fu, F.X. Ye, H.H. Wei, C. Cui: Laser surface remelting of Fe-based alloy coating deposited by APS [J]. Rare Metal Materials and Engineering, Vol. 41(2012), p. 407-413

[4]. Y.N. Wu, G. Zhang, B.C. Zhang, Z.C. Feng, Y. Liang: Laser remelting of plasma sprayed NiCrAlY and NiCrAlY-Al ${ }_{2} \mathrm{O}_{3}$ coatings [J]. Journal of Materials Science and Technology, Vol. 17(2001), p.525-528.

[5]. J. Jia: The orthorhombic design for the laser remelting of gray cast iron [J]. Journal of Shanxi University, Vol. 23(2000), p. 34-36.

[6]. P. Li, H.Y. Li, B.H. Yang, C.B. Zhang, K. Yang: Influence of laser remelting on laser cladding layer of material surface [J]. Hot working Technology, Vol. 36(2007), p. 64-66.

[7]. Q.L. Yuan, X.D. Feng, J.J. Cao, Z.J. Su: Effect of laser scanning speeds on the microstructure and corrosion resistance of laser cladding layers [J]. Laser Technology, Vol. 35(2011), p. 163-166.

[8]. C.X. Shi, Z.Y. Zhong: Development and innovation of superalloy in China [J]. Acta Metallurgica Sinica, Vol. 46(2010), p. 1281-1288.

[9]. H.Y. Wang, Y.Q. An. C.Y. Li: Research progress of Ni-based superalloys [J]. Materials Review, Vol. 25(2011), p. 482-485.

[10]. G. Wang, B.G. Zhang, J.C. Feng: Research progress in repair welding technology of Ni-based superalloy [J]. Welding and Joining, Vol. 1(2008), p. 20-23.

[11]. Y. Liu, H.T. Ye, J. Zhang: Research on cutting status of Ni-based superalloy in aviation industry [J]. Aeronautical Manufacturing Technology (2011), p. 48-51. 